\title{
Investigating the effect of animation and pamphlet-based discharge program on the self-efficacy of children with asthma
}

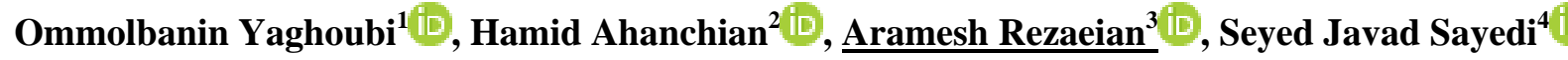 \\ ${ }^{1}$ School of Nursing and Midwifery, Mashhad University of Medical Sciences. \\ ${ }^{2}$ Department of Pediatrics, School of Medicine,Allergy Reserch Center, Ghaem Hospital, Mashhad University of Medical Sciences. \\ ${ }^{3}$ Corresponding author; Department of Pediatrics, School of Nursing and Midwifery, Mashhad University of Medical Sciences. \\ Tel: $09121759558 \quad$ fax: - Email:RezaeianA@mums.ac.ir \\ ${ }^{4}$ Department of Pediatrics, School of Medicine, Neonatal Research Center,Akbar Hospital, Mashhad University of Medical \\ Sciences.
}

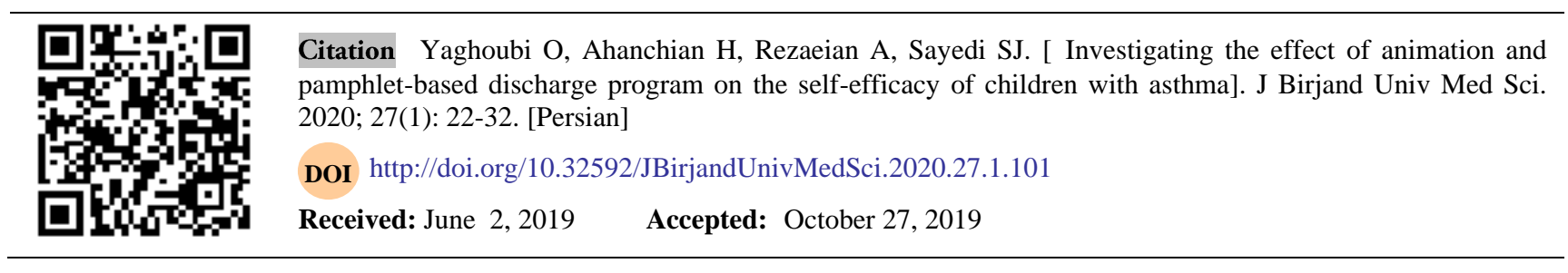

\begin{abstract}
Background and Aim: Asthma is the first cause of absenteeism and the third cause of hospitalization for children under the age of 15. It is causes psychological and emotional problems, decrease self-esteem. Lack of control of it can lead to frequent hospitalization of affected children. Perhaps providing information in an attractive way about their illness will improve their self-efficacy. Therefore, the present study aims to evaluate the effect of animation and pamphlet-based discharge program on the self-efficacy of children with asthma was designed.

Materials and Methods: This randomized clinical trial was conducted in Akbar Hospital in 2018, with participation of 90 patients that randomly allocated three groups of 30 animation, pamphlet and control. In the animation group, given educational CD and pamphlet group given educational pamphlet for twice a week about 2 months, and in the control group, information was provided in the routine section. Before and after intervention, self efficacy of children was measured. Data were analyzed by SPSS software version 16 and one way ANOVA, Kolmogorov-Smirnov, Kruskal Wallis, paired t-test, Chi-square tests and Tukey post hoc.

Results: After the intervention, the self-efficacy score of the animation group was significantly higher than the pamphlet and control group ( $\mathrm{p}<0.001)$. In comparison, intra-group self-efficacy was significantly increased in all three groups after two months compared to baseline $(\mathrm{p}<0.001)$.

Conclusion: The discharge program based on animation promotes self-efficacy in children with asthma and is recommended paying more attention to nursing care.
\end{abstract}

Key Words: Animation, Asthma, Child, Self-efficacy 


\section{بررسى تأثير بر نامه ترخيص مبتنى بر انيميشن و يمفلت بر خودكار آمدى كودكان مبتلا به آسم}

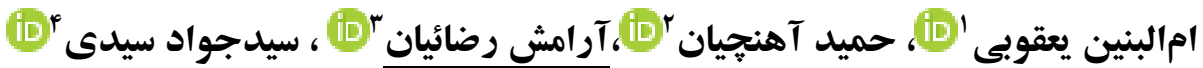

\section{جكکب:}

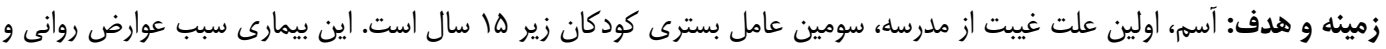

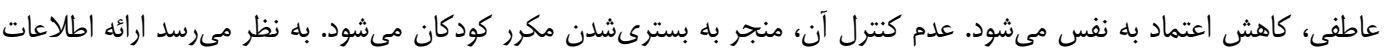

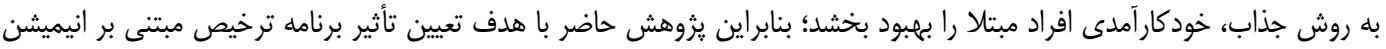

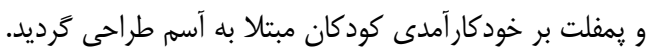

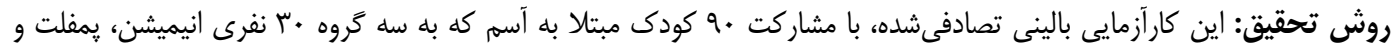

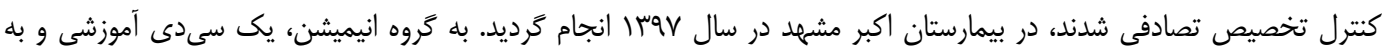

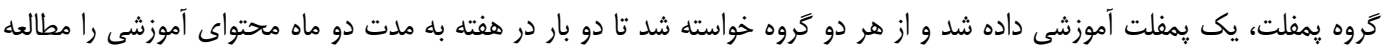

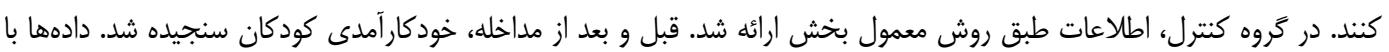

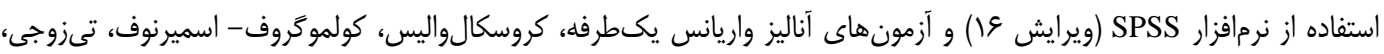
كاىاسكوئر و آزمون تعقيبى توكى تحليل شدار إندا

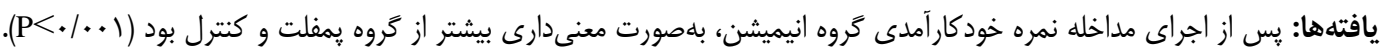

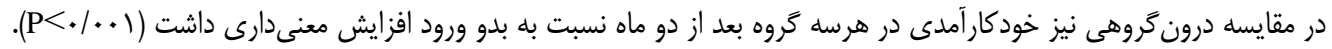

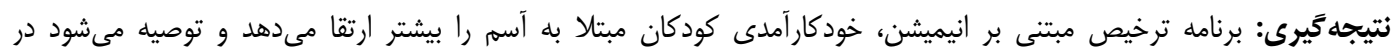

$$
\text { مراقبتهاى يرستارى توجه بيشترى به آن شود. }
$$$$
\text { وازههاى كليدى: انيميشن؛ آسه؛ كودى؛ خودكار آمدى }
$$

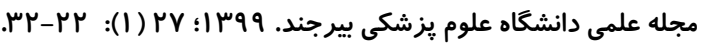

$$
\text { دريافت: r/ }
$$

' دانشكده برستارى و مامايى، دانشكاه علوم يزشكى مشهد.

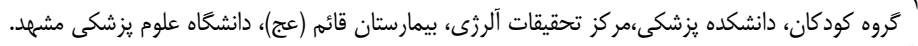

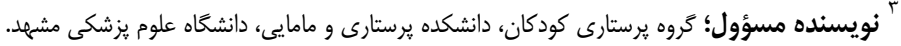

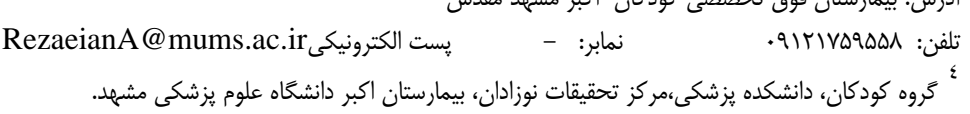




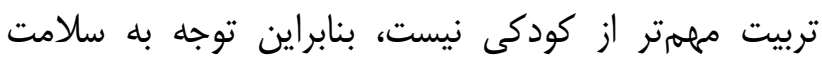
جسمى، روانى و اجتماعى كودى از اهميت شايانى برخوردار

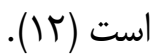

در حال حاضر برنامه ترخيص مؤثثر و منسجمى براى

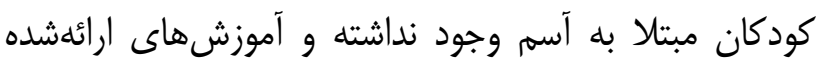

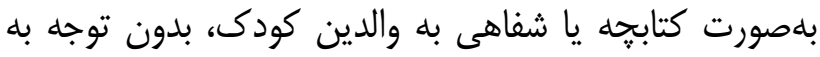

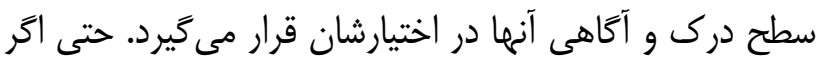

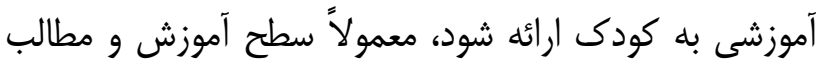
آموزشى متناسب با دوره سنى كودى نيست؛ هرا كها كها

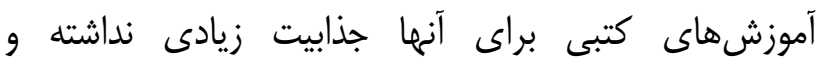

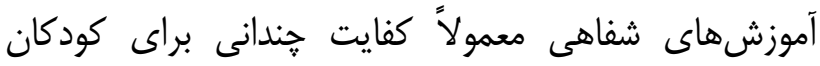
ندارد. بنابراين كودى در روند كنترل بيمارى، وابسته به بهائ

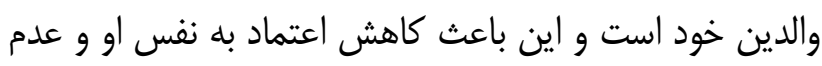
حضور وى در عرصههاى مختلف اجتماعى، علمى و ورزشى إنى

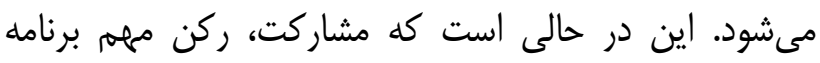

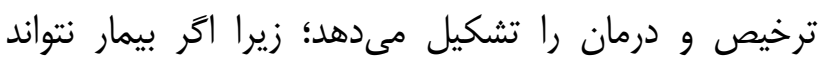

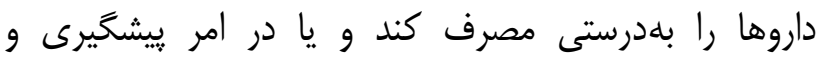

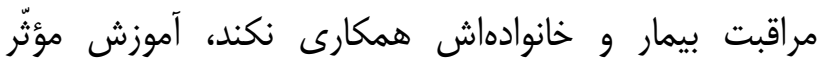
نخواهد بود (سا).

در تمامى دستور العمل هاى نوين راهنماى درمان آسه، بر درائ

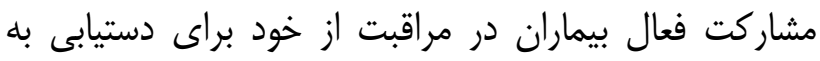

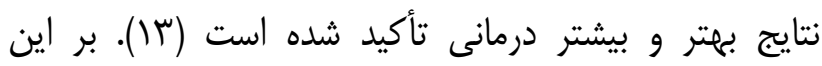

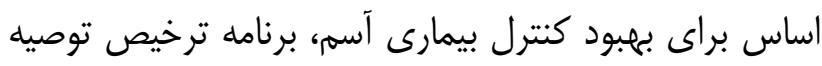

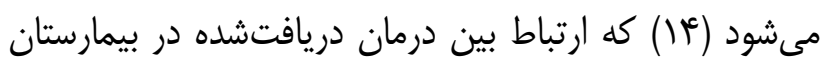

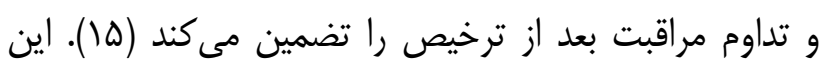

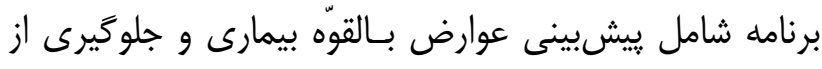

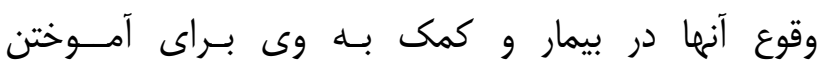

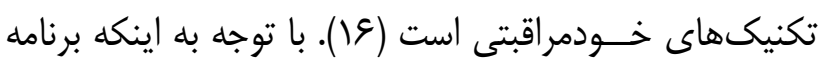

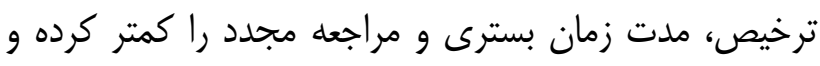

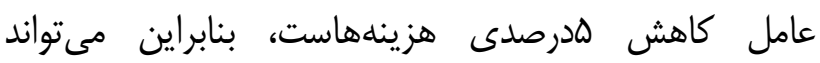

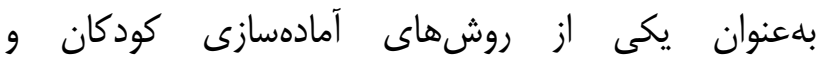
خانوادههايشان براى اين بيمارى توصيه شود (IV). البته
مقدمه - - مقد

بيمارى آسم شايعترين بيمارى مزمن دوران كودكى است

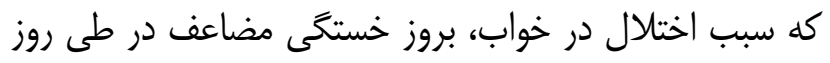

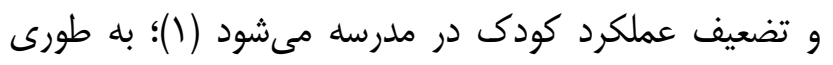

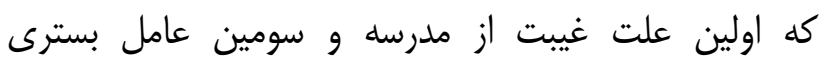

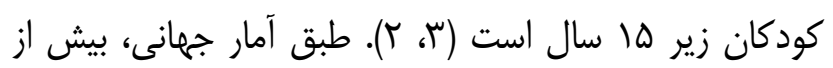

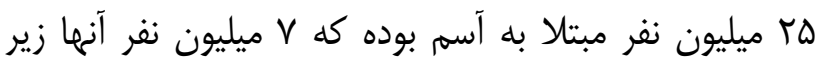

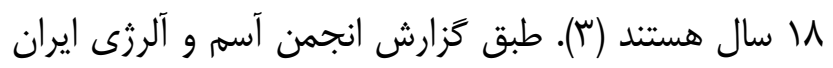

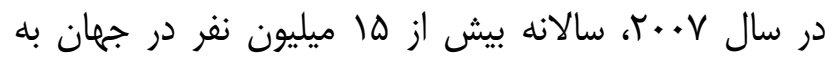

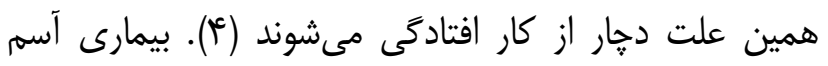

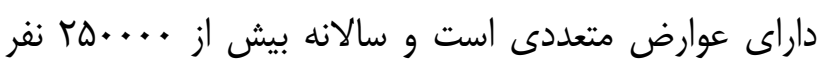

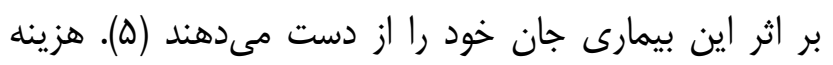

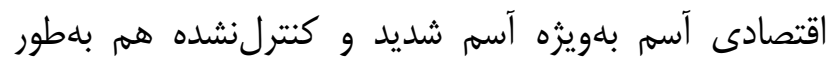

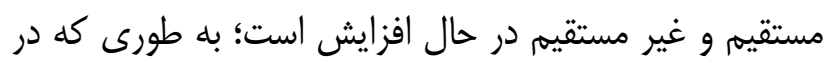

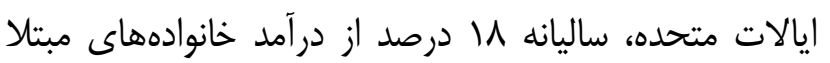

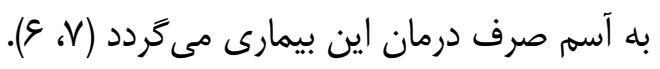

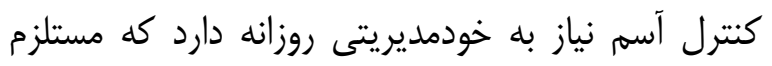

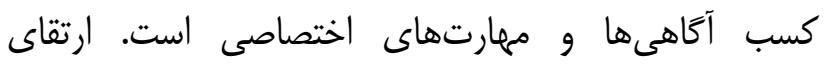

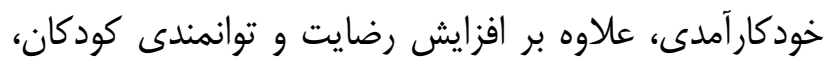

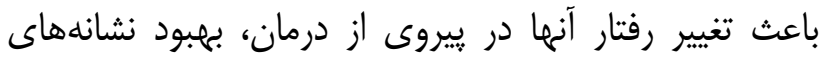

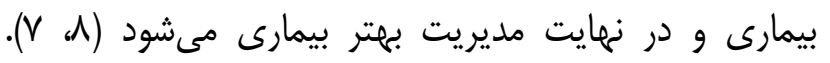

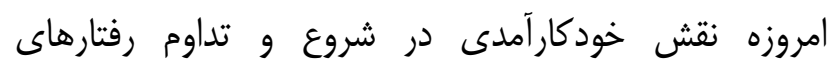

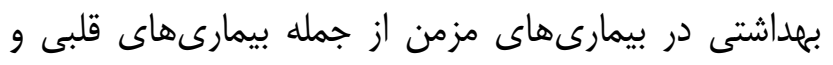

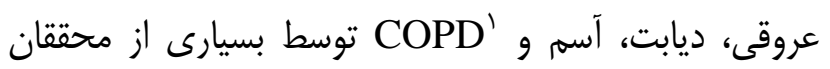

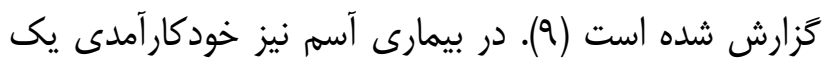

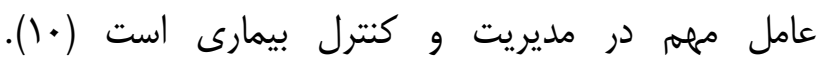

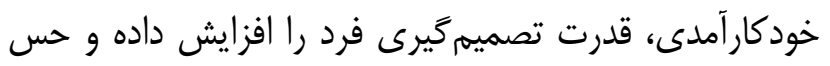

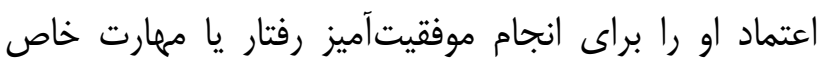

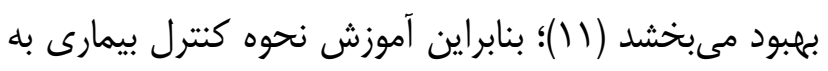

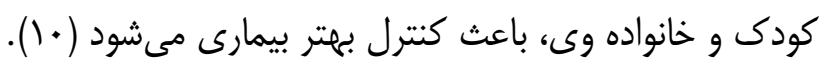

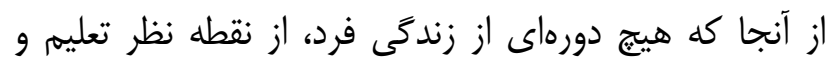

${ }^{1}$ Chronic obstructive pulmonary disease 
باور نسبت به توانايىهاى خود در كنترل افكار، احساسها و

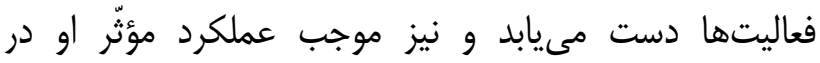

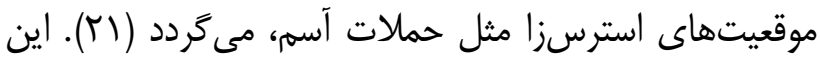

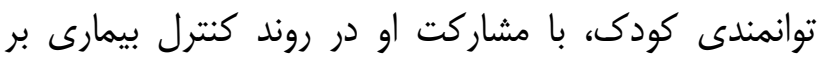

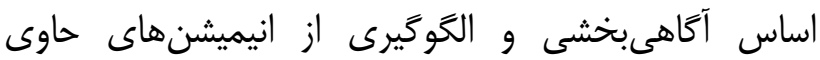

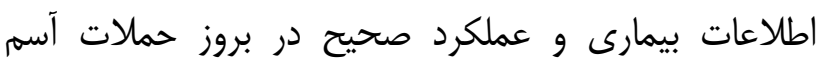

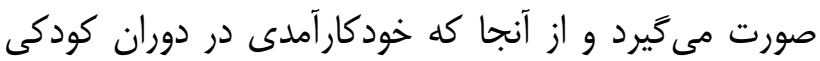

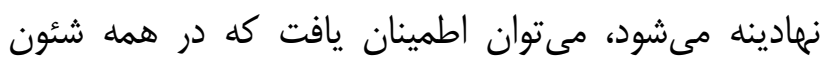

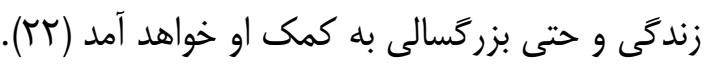
با توجه به افزايش روزافزون تعداد بيماران مبتلا به به آسم

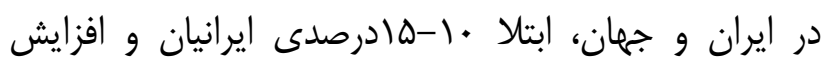

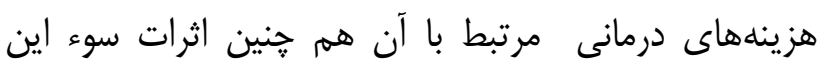

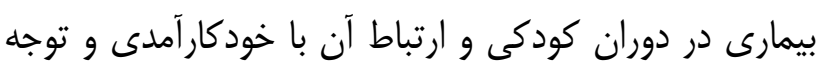

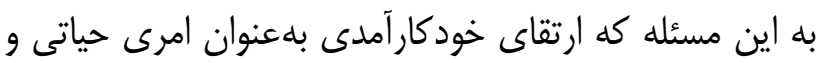

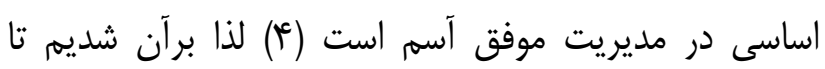
مطالعه حاضر، با هدف تعيين تأثير برنامه ترخيص مبتنى بر موريت استر

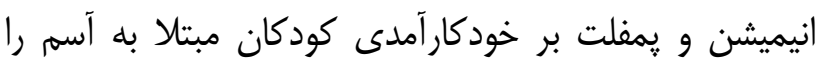

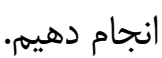

\section{روش تحقيق}

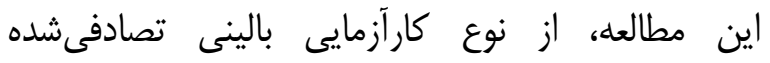

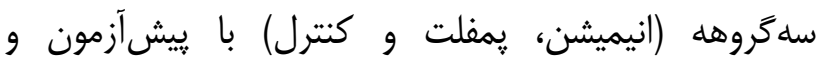
يسآزمون بود كه در بخش آسم و آلرزى بيمه بيمارستان

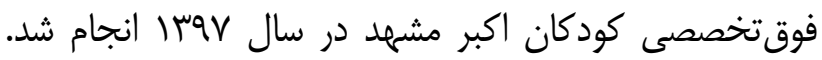

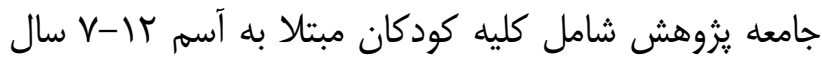
بسترى بود. حجم نمونه بر اساس مطالعه گنججه و همكاران

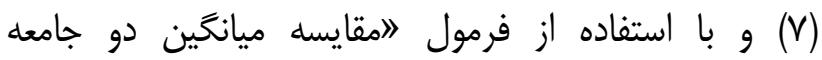
مستقل" محاسبه شد؛ بدينترتيب حجم نمونه با سطح

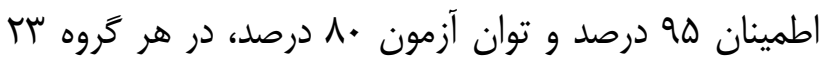

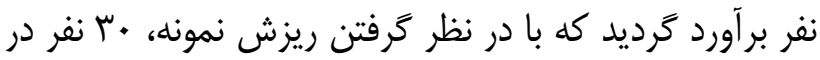
هر گروه و در مجموع • ج نفر مورد مطالعه قرار گرفتند.

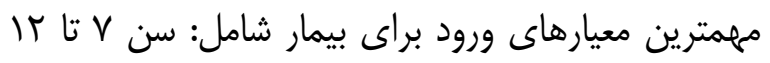

آموزشها بايد با استفاده از ابزار آموزشى مناسب براى كودكان

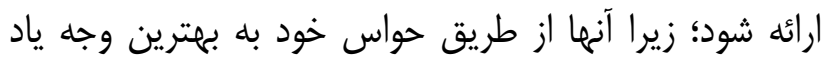

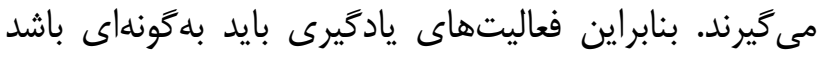

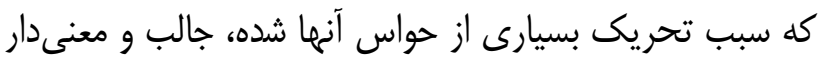

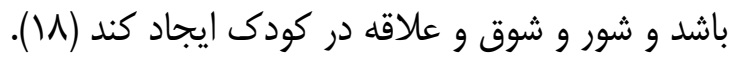

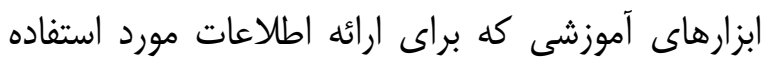

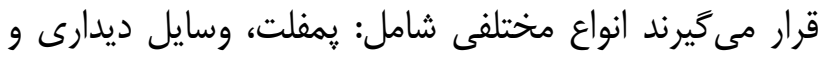

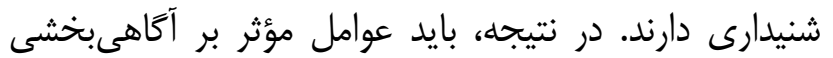
مانند: سن، جنس، ميزان تحصيلات، وضعيت فرهنكى، زبان،

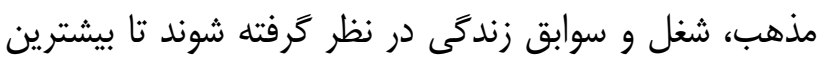
حواس (ديدارى و شنيدارى) دركير شوند (19). يمفلت، ابزار

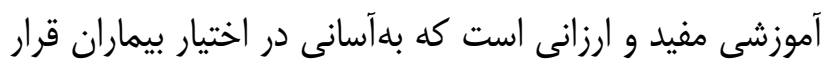

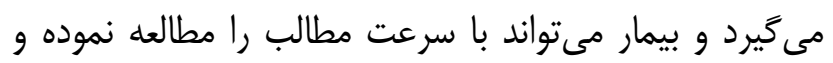

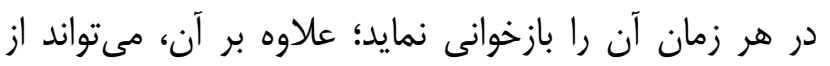

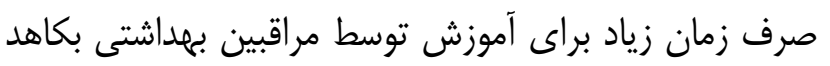

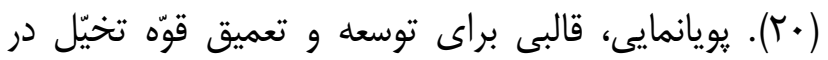

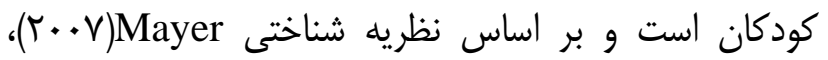

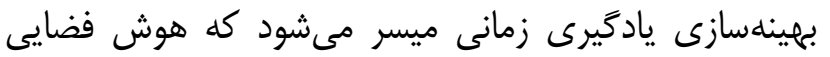

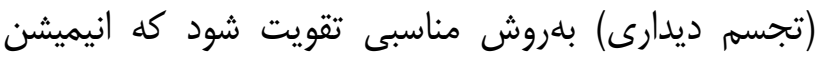

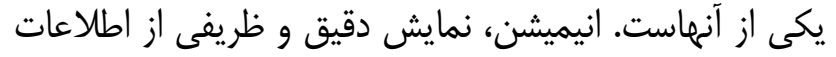

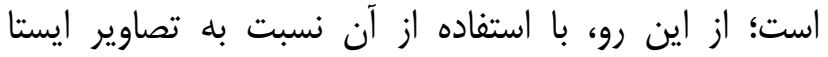

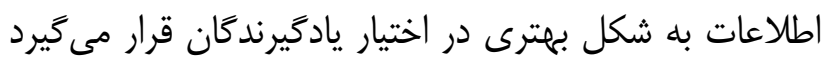

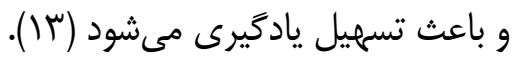

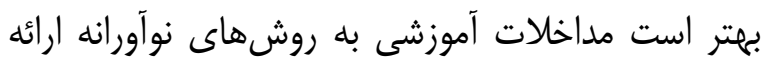

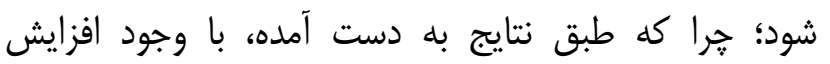

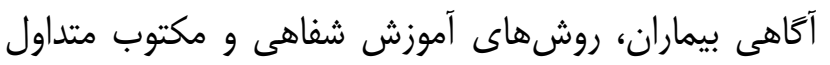

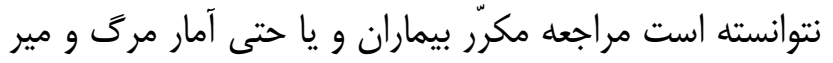

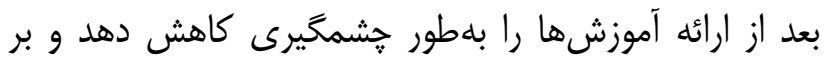

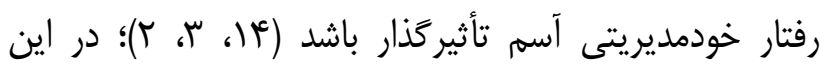

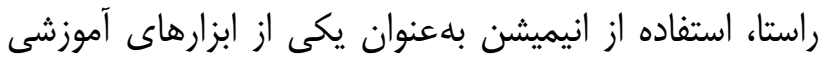

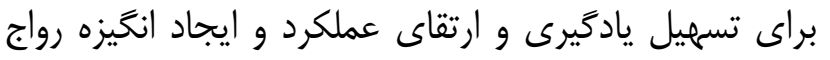

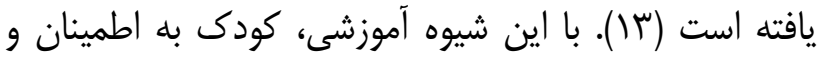


هستم) نمرددهى مى شود. كمترين نمره عا أو بيشترين نمره مى V.

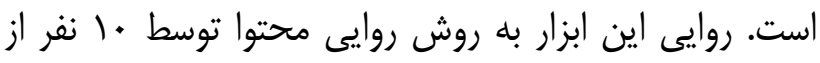

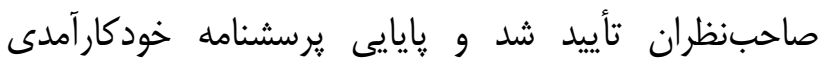

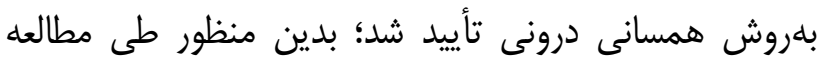

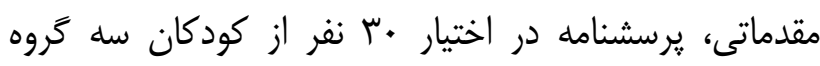

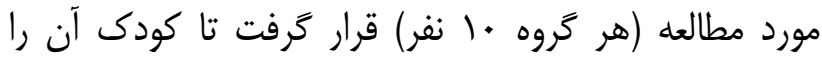

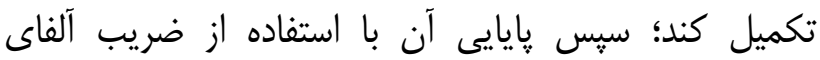

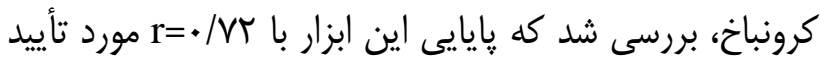

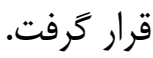
اين مطالعه در دو مرحله قبل از مداخله و مداخله صورت

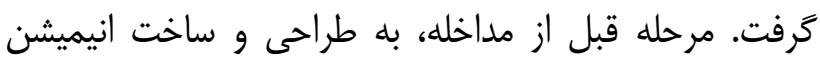

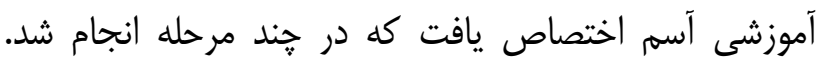

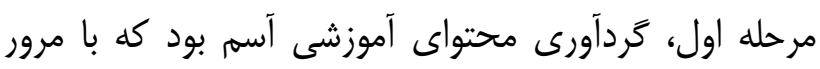

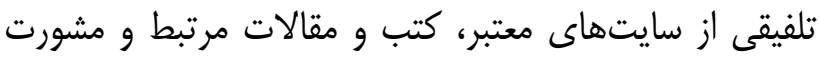

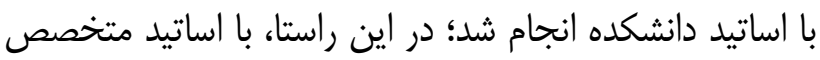

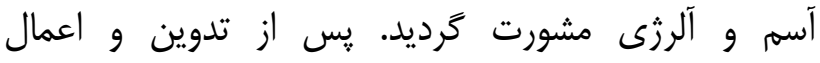

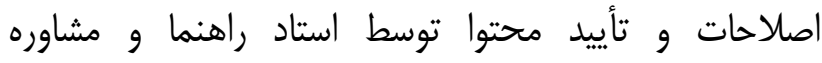
تخصصى آسه، مرحله اول به پِايان رسيد. مرحله دوم، تبديل

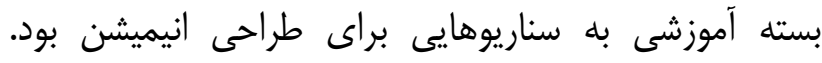

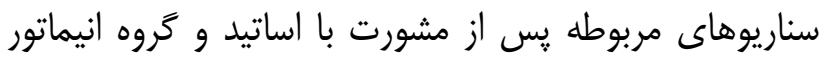

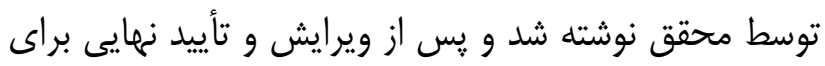

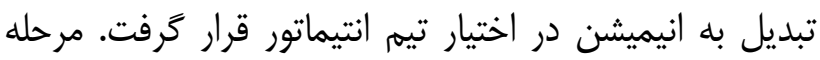

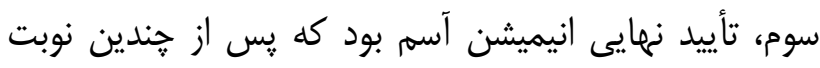

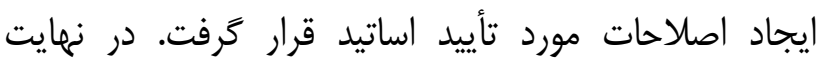

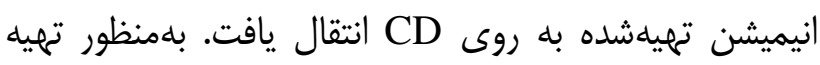

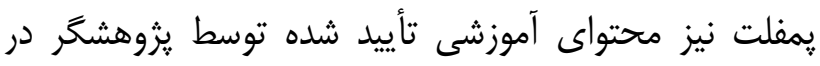

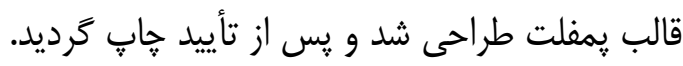
يزوهشكر يس از تأييد طرح توسط كميتهى اخلاق دانشخاه علوم يزشكى مشهد و كسب معرفىنامه از تحصيلات

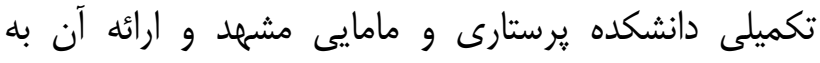
رياست محترم بيمارستان اكبر مشهل، براى شروع نمونه يُيرى
سال، تشخيص قطعى آسم توسط يزشك فوق تخصص، عدم

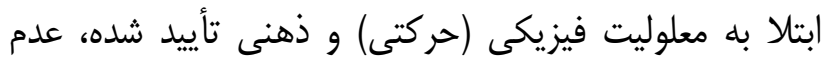

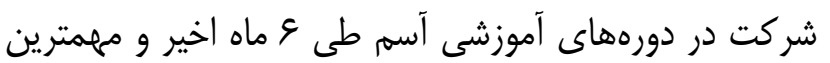
معيارهاى خروج شامل: فوت بيمار، وقوع حادثهاى كه اهن توانايى جسمى و ذهنى كودى را مختل نمايد و عدم تمايل بهائ به ادامه مشاركت در مطالعه به هر دليلى بود. بس از كسب مجوز از كميته اخلاق دانشخاه، هماهنكى با نيا

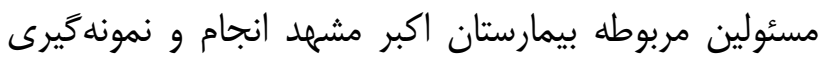

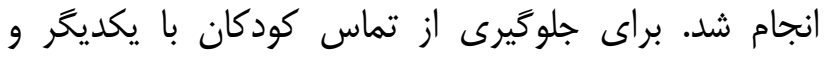

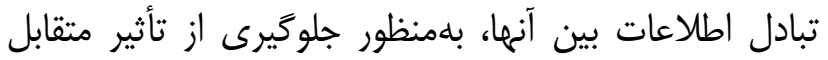

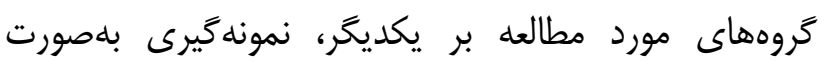

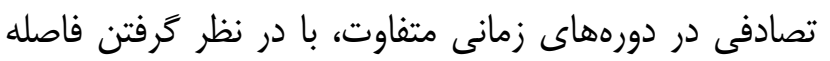

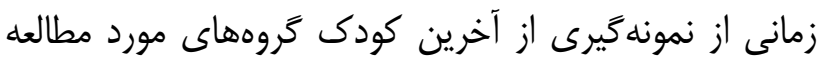

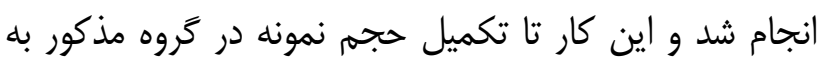

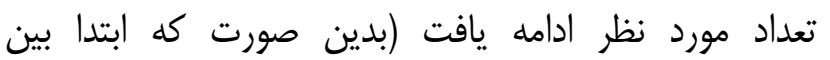

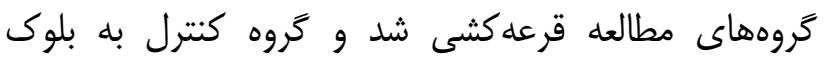

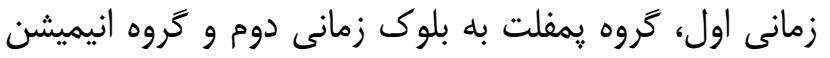

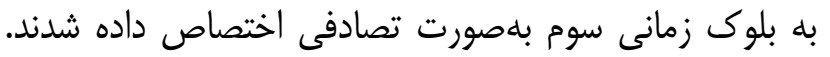

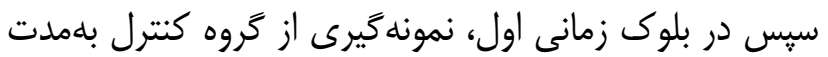

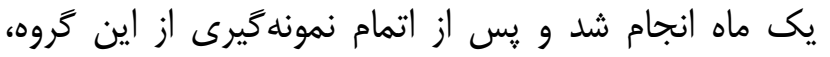

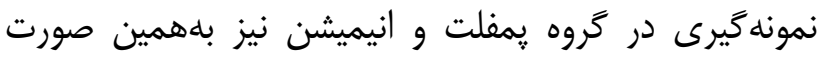

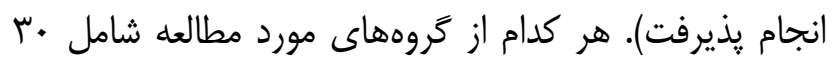

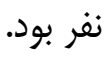
ابزارهاى مورد استفاده در اين مطالعه شامل فرم

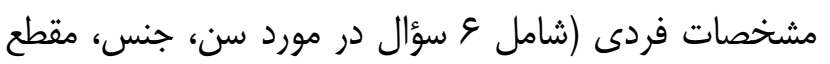
تحصيلى، مدت زمان ابتلا به آسه، سابقه ابتلا در بستخان درنان

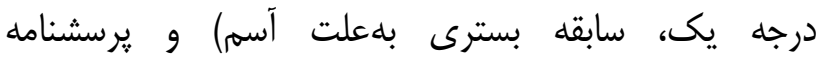
خودكار آمدى آسم كودكان بود. يرسشنامه خودكار آمدى آسم بهم كودكان براى اولين بار توسط Bursch و همكاران (1999)

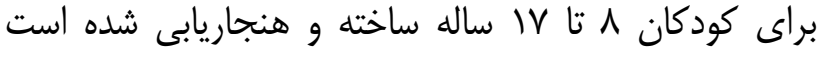

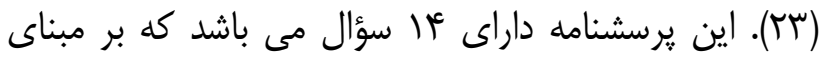

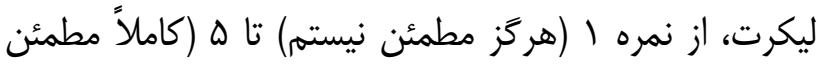


روز يس از تحويل انيميشن و پيمفلت) با كليه كودكان تماس

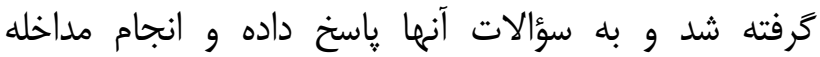

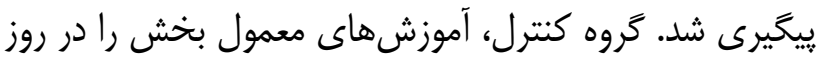

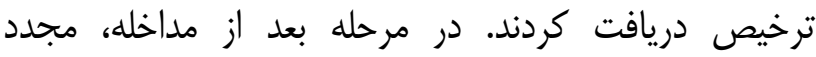

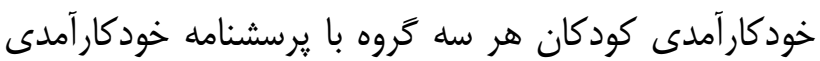
آسه، مورد ارزيابى قرار كرفت.

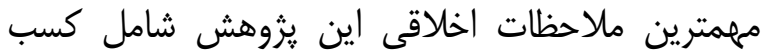

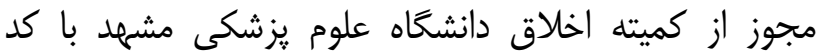

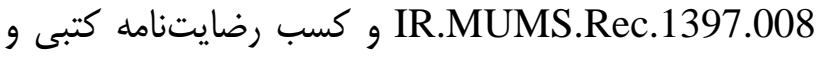
آكاهانه از شركت كنندهها بود؛ همجنين اين مطالعه با كد IRCT.20181231042184N1 ايران نيز مورد تأييد قرار كرفت. دادهها يس از جمعآورى و

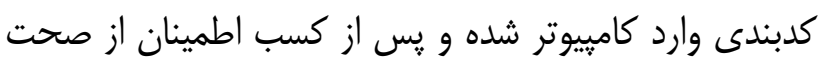

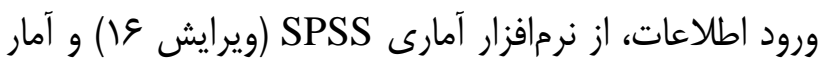

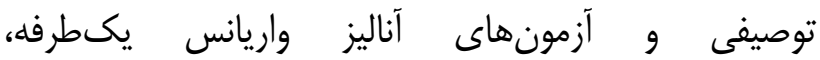
كروسكالواليس (با توجه به عدم برخوردارى متغير سن و و ونهاي

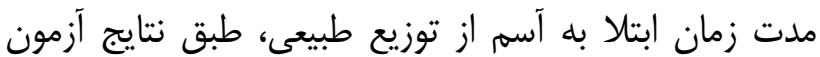

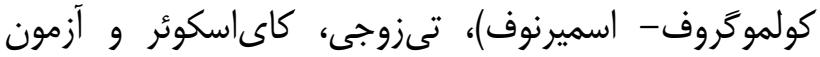
تعقيبى توكى براى خلاصهكردن و تحليل آنها استفاده شد.

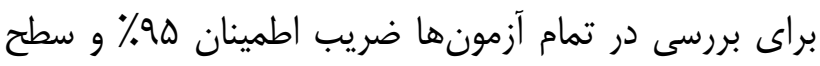

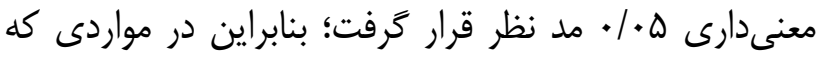

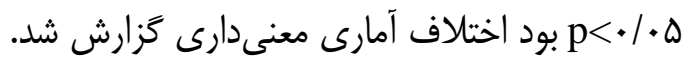

يافتهها طبق نتيجه آزمون كروسكالواليس، ميانكين سن سن كودكان گروه انيميشن

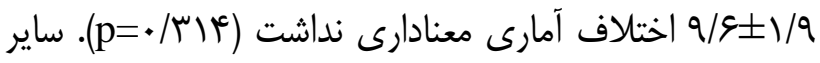

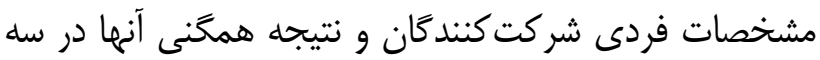
كروه در جدول يك ذكر شده است.
به بخش آسم و آلرزى اين بيمارستان معرفى شد. مراحل كار و مزاياى اجراى طرح براى سريرستار و والدين محترم توضيح

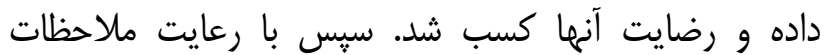

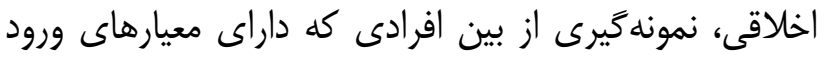

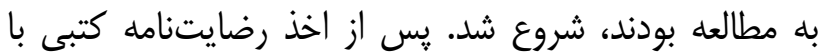

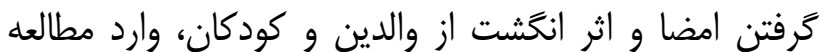

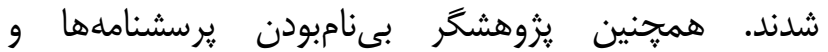
محرمانهماندن اطلاعات را براى آنها توضيح داد و از واحدهاى بترني

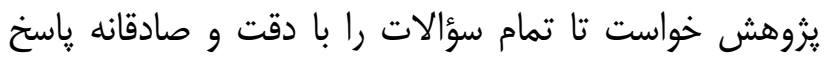

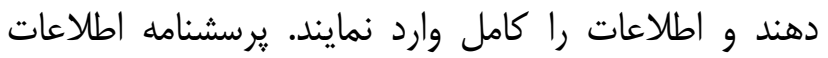
فردى و بيمارى نيز براى كودكان هر سه گروه مورد ماط مطالعه

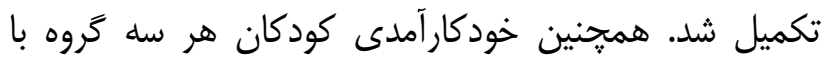
يرسشنامه خودكارآمدى آسم سنجيده شدين

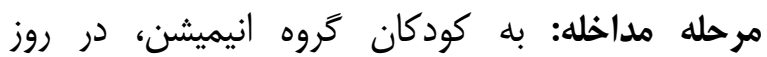
ترخيص سىدى حاوى انيميشن آموزشى آسم و به كرونه

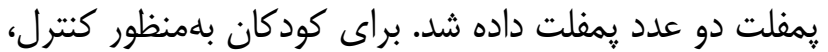

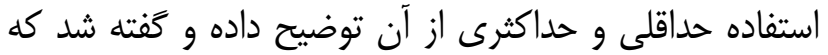

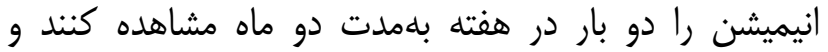

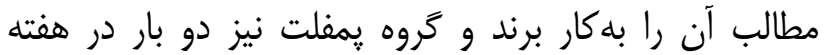

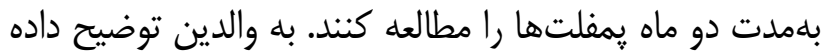
شد كودكانى كه كمتر از مقدار تعيينشده سى ردى مطى را مشاهده

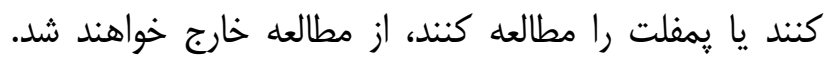

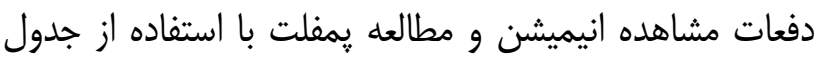
ثبت زمانى كه در اختيار والدين كودكان هر دو گروه مداخ مداخله

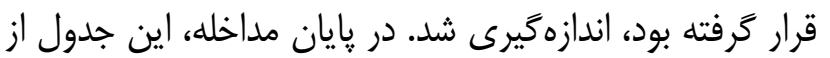

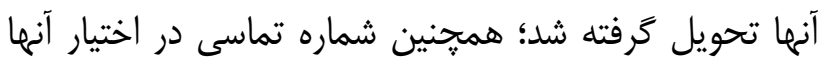

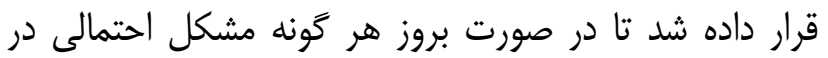

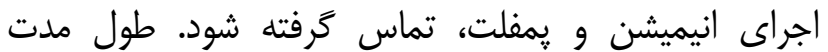

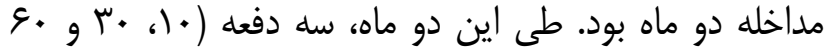


جدول ا- مقايسه مشخصات فردى و طبى كودكان مورد مطالعه در سه تَروه مورد مطالعه

\begin{tabular}{|c|c|c|c|c|c|}
\hline نتيجه آزمون & 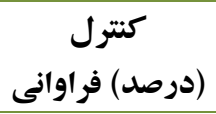 & (درصد) فراوانى & (درصد) فراوانى & & متغيّر \\
\hline \multirow{2}{*}{$* \mathrm{p}=\cdot / / \wedge \Delta$} & I & $q(r \cdot / \cdot)$ & $19(\Delta \mu / \mu)$ & دختر & \multirow[b]{2}{*}{ 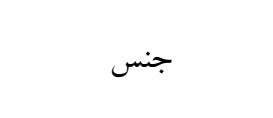 } \\
\hline & IV $(\Delta 9 / V)$ & $Y I(V \cdot / \cdot)$ & If (FG/V) & & \\
\hline \multirow{6}{*}{$* * \mathrm{p}=\cdot / \mathrm{r \Delta r}$} & $\Delta(19 / \mathrm{V})$ & 1. $(r / \Gamma)$ & $\Delta(19 / V)$ & اول دبستان & \multirow{6}{*}{ مقطع تحصيلى } \\
\hline & $\Delta(19 / V)$ & $q(Y \cdot / \cdot)$ & $\Delta(19 / V)$ & دوم دبستان & \\
\hline & $f(\mid r / T)$ & $r(1 \cdot / \cdot)$ & $9(Y \cdot / \cdot)$ & سوم دبستان & \\
\hline & $9(Y \cdot / \cdot)$ & $F(\mid r / \mu)$ & $9(Y \cdot / \cdot)$ & جهارم دبستان & \\
\hline & $r(\boldsymbol{G / V})$ & $r(9 / V)$ & $F(\mid \mu / \mu)$ & ينجم دبستان & \\
\hline & $\wedge(Y G / V)$ & $\Delta(19 / V)$ & $F(\mid \mu / \mu)$ & ششم دبستان & \\
\hline$* * \mathrm{p}=\cdot / 99 \mathrm{~V}$ & $r / 9 \pm \cdot / 9$ & $r / 9 \pm \cdot / V$ & $r / 9 \pm \cdot / V$ & & مدت زمان ابتلا به آسم \\
\hline \multirow{2}{*}{$* p=\cdot / 4 r \Delta$} & If $(F q / V)$ & $19(9 \mu / \Gamma)$ & IV $(\Delta Y / V)$ & بلى & \multirow{2}{*}{ سابقه ابتلاى اعضاى } \\
\hline & $19(\Delta \mu / \Gamma)$ & $11(\mathrm{rG} / \mathrm{V})$ & $\|(\boldsymbol{K} / \boldsymbol{\mu})$ & خير & \\
\hline \multirow{4}{*}{$* * \mathrm{p}=\cdot / \cdot \mathrm{v}}$. & rG $(\Lambda 9 / \mathrm{V})$ & $\mathrm{rq}(99 / \mathrm{V})$ & $r \cdot(1 \cdots / \cdot)$ & يكك بار & \multirow{4}{*}{ سابقه بسترى به علت } \\
\hline & $r(V / V)$ & $\cdot(\cdot / \cdot)$ & $\cdot(\cdot / \cdot)$ & دو بار & \\
\hline & $1(\boldsymbol{\mu} / \boldsymbol{\mu})$ & $\cdot(\cdot / \cdot)$ & $\cdot(\cdot / \cdot)$ & سه بار & \\
\hline & $1(\Gamma / \mu)$ & $1(r / \Gamma)$ & $\cdot(\cdot / \cdot)$ & جهار بار & \\
\hline
\end{tabular}

*: Chi square, **: Kruskalwallis

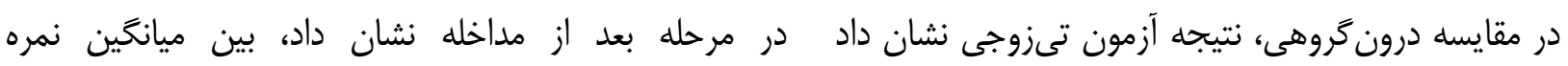

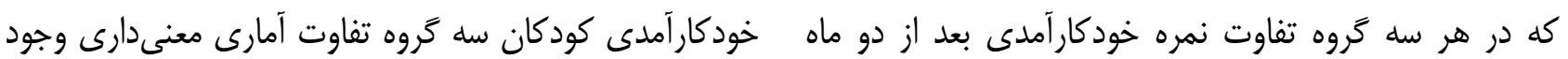

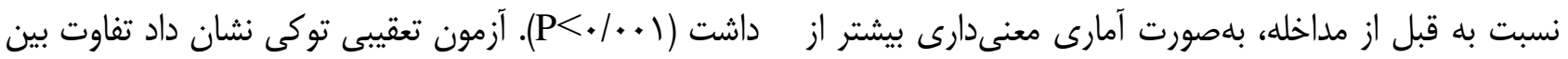

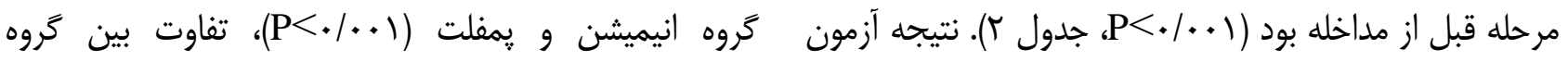

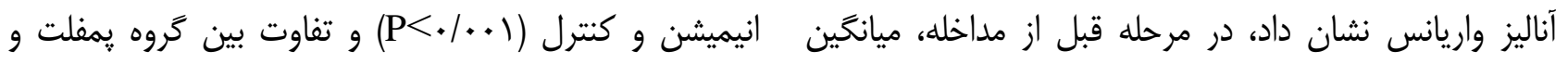

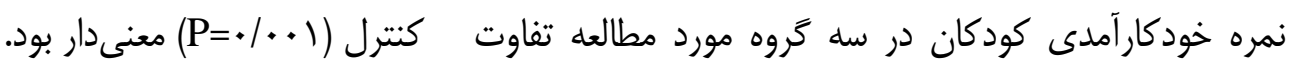

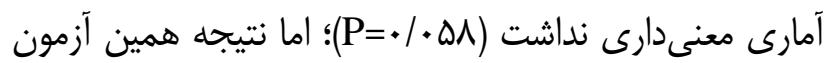


جدول ץ- مقايسه ميانكَين و انحر اف معيار نمره خودكار آمدى كودكان مبتلا به آسم مورد مطالعه در مراحل مداخله در سه تَروه

\begin{tabular}{|c|c|c|c|c|}
\hline \multirow{4}{*}{ 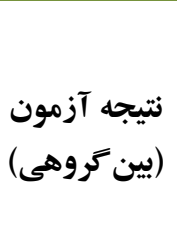 } & \multicolumn{3}{|c|}{ تروه } & \multirow{4}{*}{ نمره خود كار آمدى } \\
\hline & 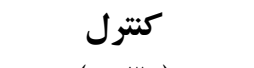 & هِمفلت & انيميشن & \\
\hline & 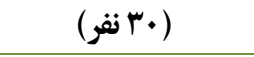 & 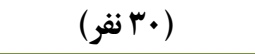 & ( إنقر) & \\
\hline & انحر اف معيار دميانكين & انحر اف معيار ذميانكين & انحر اف معيار ذميانكين & \\
\hline 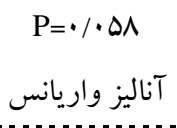 & $r \cdot / q \pm r / q$ & $r F / \cdot \pm V / r$ & $r F / \Lambda \pm \Delta / r$ & ق ق قبل از مداخله \\
\hline 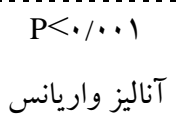 & $r V / I \pm \Delta / q$ & $\mathrm{rF} / \cdot \pm \mathrm{V} / \mathrm{I}$ & $\Delta \Delta / \Upsilon \pm \Lambda / \Lambda$ & بعد از دو ماه \\
\hline 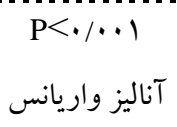 & $9 / r \pm r / V$ & $1 \cdot / \cdot \pm r / 9$ & $\mathrm{rl} / \cdot \pm 9 / 9$ & تفاوت بعد از دو ماه نسبت به بلدو ورود \\
\hline & $\begin{array}{l}\mathrm{P}<\cdot / .+1 \\
\text { تى زوجى }\end{array}$ & $\begin{array}{l}\mathrm{P}<\cdot / \cdot / \\
\text { تى زوجى }\end{array}$ & $\begin{array}{l}\mathrm{P}<\cdot / \cdot / \\
\text { تى زوجى }\end{array}$ & نتيجه آزمون درون گروهى \\
\hline
\end{tabular}

و خودكار آمدى افراد گروه آزمايش را در مقايسه با گروه كنترل نتايج مطالعه حاضر نشان داد در مرحله بعد از مداخله، بهبود بخشيده است كه از اين جهت با مطالعه حاضر همسو

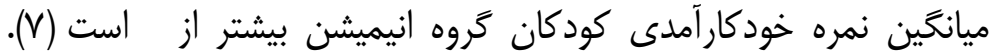
Joshi كروه يمفلت و كنترل بود. اقوامى و همكاران (•وسا) در مطالعه خود با عنوان خودآموزى برنامه كامييوترى آموزش كودكان مبتلا به آسم مقايسه تأثير أموزش به دو روش گروهى و لوح فشرده بر شديد در بخش اورزانس انجام دادند و دريافتند، به كارگيرى

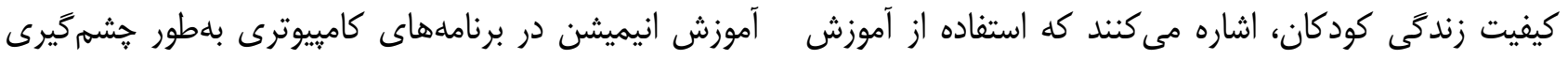

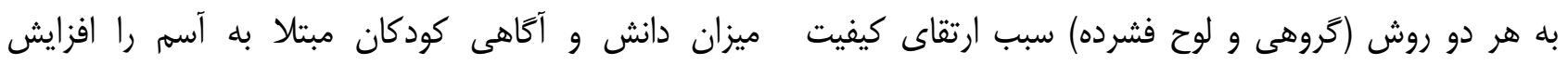

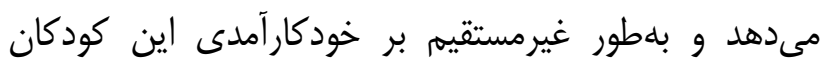

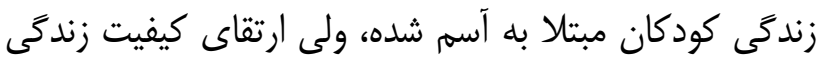
تأثير داشته و آن را بالا مىبرد (rه) Krishna קندرسانهاى را براى كودكان مبتلا به آسم مورد بررسى قرار

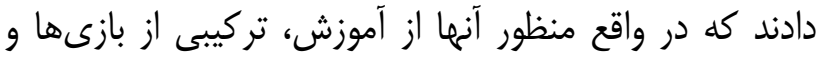
نقاشىهاى متحرى كامبيوترى بود. نتايج مطالعه آنها نشان

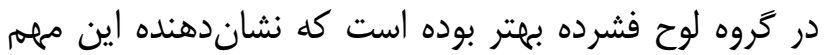

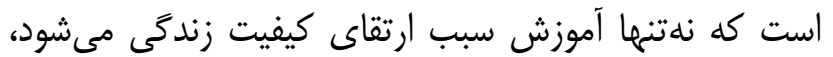

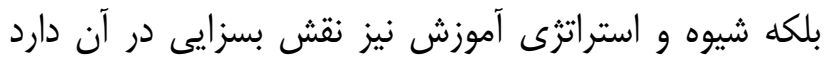

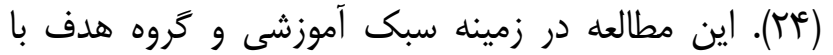
داد كه استفاده تركيبى از آموزشها با مراقبتهاى دهري درمانى، مىتواند اثرات مفيدى به همراه داشته باشد (عآ). مطالعه

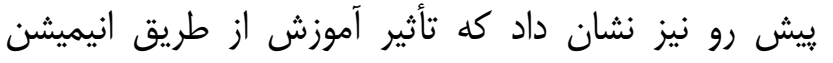
بيشتر از تأثير آموزش با يمفلت بر خودكارآمدى كودكان مبتلا مطالعه حاضر همسو است.

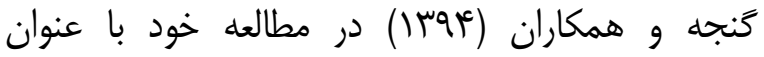

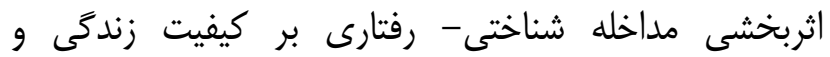

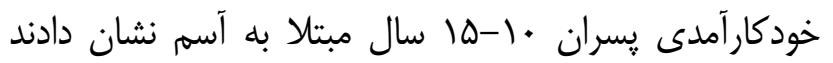

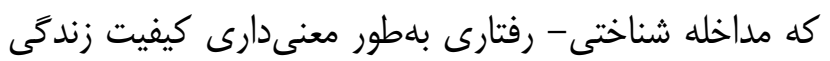


است كه حكايت از يك متغير مداخله اثر اين مداخله آموزش انيميشن و حتى يمفلت نبوده است؛ هرا كه افزايش

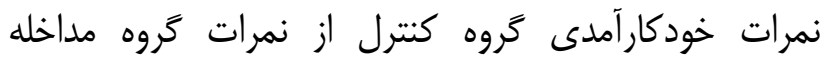

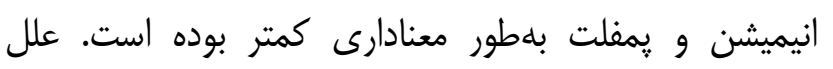

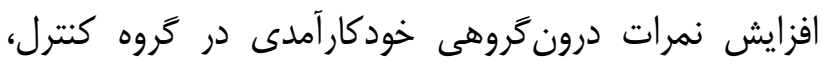

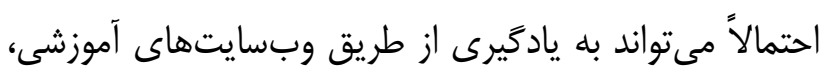
شبكههاى اجتماعى، رسانههاى ارتباط جمعى (مانند: راديو،

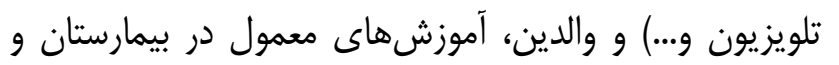

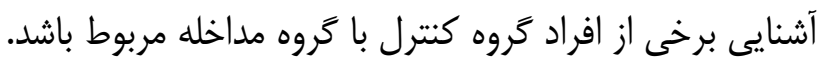

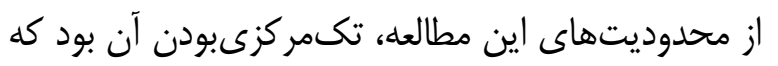

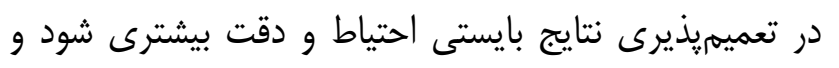
در مطالعات آتى مورد توجه قرار كيرد.

نتيجه كيرى

با توجه به اينكه در مطالعه حاضر برنامه ترخيص در قالب إنب

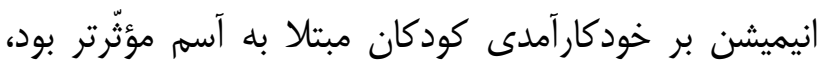
توصيه مىشود اين برنامه آموزشى براى كنترل آسم كودكان

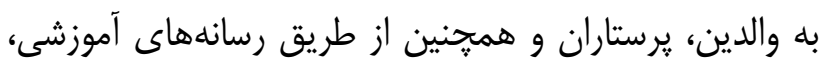
آموزش داده شود.

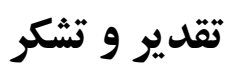

اين يزوهش نتيجه يايان نامه دانشجويى كارشناسى ارشد

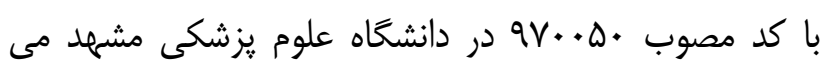

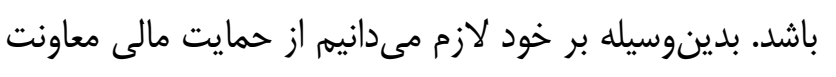

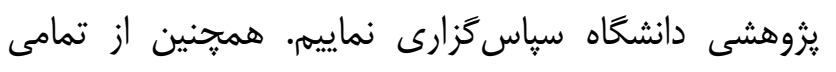
كودكان عزيز و همراهان محترم آنها و مسئولين بيمارستان

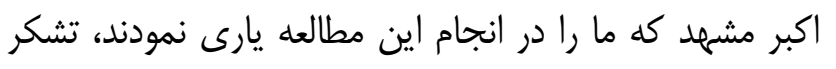
و قدردانى مىنماييم.

\section{تضاد منافع:}

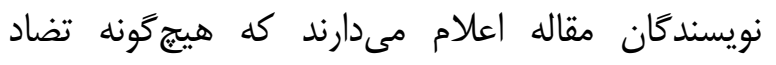
منافعى در يزوهش حاضر وجود ندارد.
به آسم است. يكى از دلايل اين امر را مىتوان در تعاملىبودن

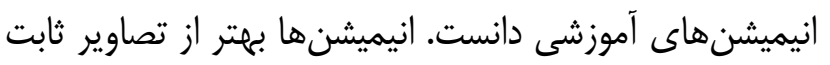

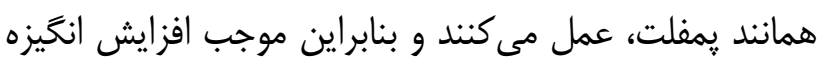

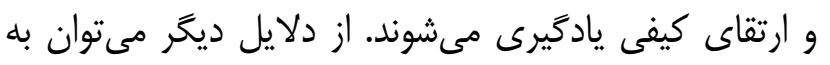

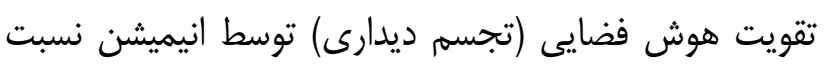
به ساير روشهاى آموزشى اشاره كرد.

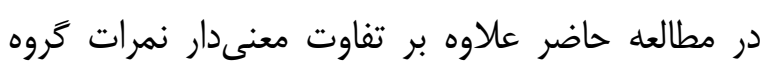

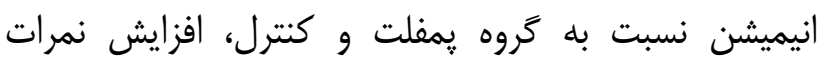

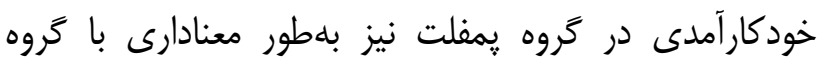

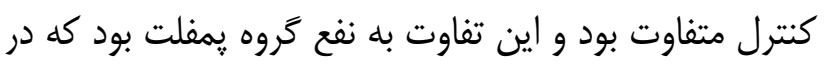
اين مورد وجه شباهتى با مطالعه Marsh و همكاران دارد.

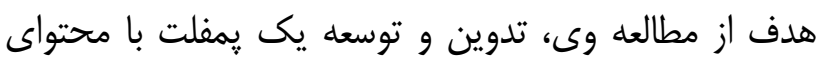

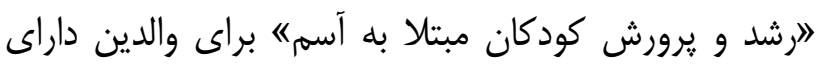

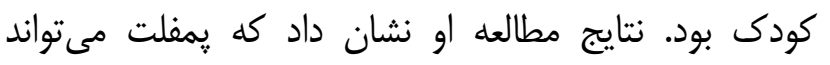

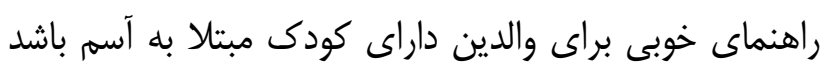

و و همكاران نيز در مطالعه خود سه نوع آموزش

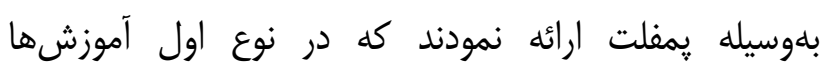
بلهورت كامل ارائه شد، نوع دوم با محتواى مختصرشده بود نداث

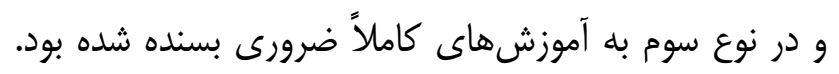

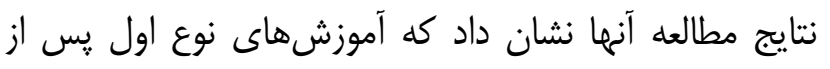

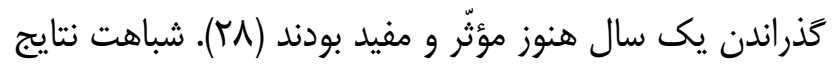

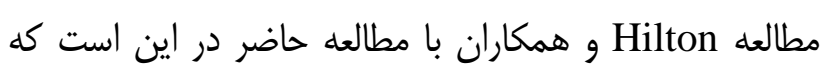

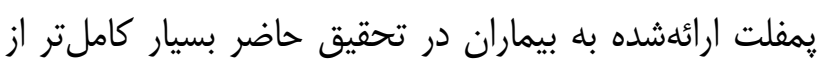

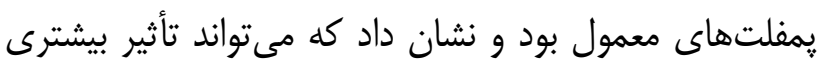
بر خودكارآمدى كودكان مبتلا به آسم داشته باشد.

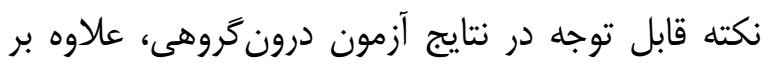

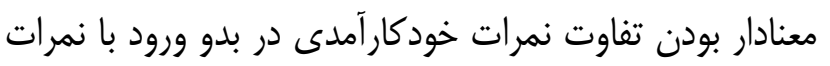

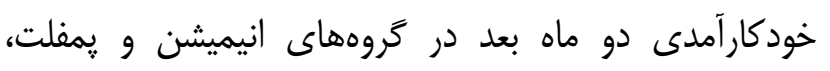

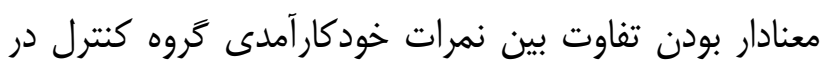

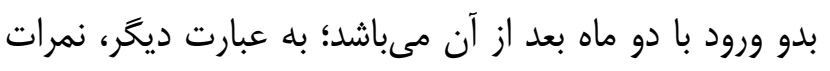

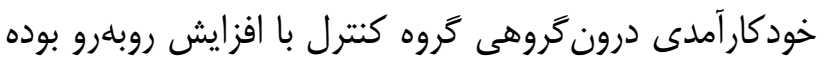




\section{منابع:}

1- Moin M, Alyasin S. Asthma Basic Sciences and Clinical Compilation. Tehran: Tehran University Press Center; 2003. [Persian]

2- Arezomaniyas S. Wongs nursing care of infants and children. $10^{\text {th }}$ ed. Tehran: Jameehnegar; 2015. [Persian]

3- Dant M, Karen J. Nelson Essentials of pediatrics. Translated by Eshraghi A, Davani Mostafazadeh B,e. $7^{\text {th }}$ ed. Tehran: Andisherafi; 2015. pp: 428 [Persian]

4- Mohajjel Aghdam A, Hasankhani H, Gharemohammadlu R, Esmaeily M. Relation of patients self-efficacy with control of asthma symptoms. J Gorgan Univ Med Sci. 2013; 15(2): 70-6. [Persian]

5- O’Byrne PM. Global guidelines for asthma management: summary of the current status and future challenges. Pol Arch Med Wewn. 2010; 120(12): 511-7.

6- Mazloomi S S, abbacimoghaddam A, Saba M A, Morovati M A, Fallahzadeh H. The Relation of Knowledge, Attitude and Self-Management Behaviors in Asthmatic Patients with Controlling Asthma. Zahedan J Res Med Sci. 2012; 14(1): 49-55

7- Ganjeh P, Mehrabizadeh Honarmand M, Davoudi I, Zargar Y. The Effectiveness of Cognitive-behavioral Intervention on the Quality of Life and Self-efficacy in 10-15 Year Boys with Asthma Symptoms in Ahvaz. Journal of Psychological Achievements. 2015; 22(1): 67-88. doi:10.22055/psy.2015.11182

8- Mohammadi pour M, Farhang N. [Effectiveness of group counseling based on acceptance and commitment in selfefficacy of pseudo-family children]. Studies of Psychology and Educational Sciences. 2018; 3(4): 88-99. [Persian]

9- Omidi A, Kazemi N, Khatiban M, Karami M. Effect of self-care education on self-efficacy in patients with chronic obstructive pulmonary disease in the Educational and Medical Centers of Hamadan University of Medical Sciences. Avicenna J Nurs Midwifery care. 2015; 23(2): 74-84. [Persian]

10- Feldman CH, Clark NM, Evans D. The role of health education in medical management of asthma some program applications. Clin Rev Allergy. 1987; 5(3): 195-205. DOI: 10.1007/bf02991194

11- Saif AA. Change in Behavioral and Behavioral Therapy (Theories and Methods). $3^{\text {th }}$ ed. Tehran: Doran; 2014

. persian

12- Valizadeh L, Bilan N, Zarei S, Sharifi A. Effect of Education and Controlling Asthma Triggers on Quality of Life among Adolescents with Asthma: A Randomized Clinical Trial. J Mazandaran Univ Med Sci. 2013; 23(98): 49-57. [Persian]

13- Entezari N, Talepasand S, Rezaie AM. The Effect of Static Pictures and Animation on Improving Learning: The Moderating Role of Visual Cues and Gender. Studies in Learning \& Instruction. 2013; 5(1): 23-46. [Persian]

14- Alaviani M, Khosravan S, hoseyni R, hoseyni M. Caring needs of discharged patients from medical-surgical wards of Gonabad hospitals. Nursing Journal of the vulnerable. 2015; 2(3): 25-35. [Persian]

15- Mohammadi A, Dalir Z, Hamzeh Gardeshi F, Ziaei S. Nurses' Viewpoints Toward the Causes of not Implementing the Discharge Planning in Burn Units in 2010. J Mazandaran Univ Med Sci. 2011; 21(83): 67-72. [Persian]

16- Sadeghi F, Kermanshahi S, Memariyan R. The effect of discharge planning on the quality of life of school-age children with congenital heart disease undergoing heart surgery. Avicenna J Nurs Midwifery Care. 2013; 21(1): 15-25. [Persian]

17- Ranjbar F, Ghanbari B, Khaleghparast S, Manouchehri H, Nasiri N. The Effects of Discharge Planning on Insight, Symptoms and Hospitalization of Schizophrenia Patients at Iran University of Medical Sciences Hospitals. Iran J Psychiatry Clin Psychol. 2011; 17(1): 53-9. [Persian]

18- Moradi R, Sharifidaramadi P. The Effect of Multimedia Social Skills Training on Social Skills Development of Second Grade Female Deaf Students in Middle School. Journal of Researches of Cognitive and Behavioral sciences. 2015; 4(2):131-44. [Persian] 
19- movallali G, rezaiyan F. An overview of the use of Multimedia in Learning Disabilities. Exceptional Education. 2017; 4(147): 49-56. [Persian]

20- Noorian K, Rajaei M, Moazeni M, Aein F. Compare the effectiveness of face-to-face educationwithleaflet on preoperative knowledge of patients undergoing elective surgery- A randomized clinical trial. J Clin Nurs Midwifery. 2013; 2(3): 1-7. [Persian]

21- Braun E, Baidusi A, Alroy G, Azzam ZS. Telephone follow-up improves patients satisfaction following hospital discharge. Eur J Intern Med. 2009; 20(2): 221-5. doi: 10.1016/j.ejim.2008.07.021.

22- Shariati M, Fazilat pour M, Hoseinchari M. [The role of social self-efficacy interfaces between attachment to peer group and parents with loneliness in high school students]. Studies in Learning \& Instruction. 2016; 8(1): 27-49. [Persian] doi: 10.22099/jsli.2016.3822

23- Bursch B, Schwankovsky L, Gillbert J, Zeiger K. Construction and validation of four childhood asthma selfmanagement scales: Parent barriers, child and parent self-efficacy and parent belief in treatment efficacy. J Asthma. 1999; 36(1): 115-28. DOI: 10.3109/02770909909065155

24- Aghvamy M, Mohammadzadeh S, Gallalmanesh M, Zare R. Assessment the Education Compariment to Two Ways: Groupe Education and Computer Education on Quality of Life in the Children 8-12 Years Suffering from Asthma in the Valiasr Hospital of Zanjan. J Adv Med Biomed Res. 2011; 19(74): 78-85. [Persian]

25- Joshi A, Lichenstein R, King J, Arora M, Khan S. Evaluation of a Computer-Based Patient Education and Motivation Tool on Knowledge, Attitudes and Practice towards Influenza Vaccination. Int Electron J Health Educ. 2009; 12: 1-15.

26- Krishna S, Balas EA, Francisco BD, Konig P. Effective and sustainable multimedia education for children with asthma: A randomized controlled trial. Children's Health Care. 2006; 35(1): 75-90. doi: 10.1207/s15326888chc3501_7

27- Marsh M. A report on the development and evaluation of a booklet entitled Growing up with asthma - a guide for parents [MS Dissertation]. Newfoundland, Kanada: Memorial University; 1983.

28- Hilton S, Anderson HR, Sibbald B, Freeling P. Controlled evaluation of the effects of patient education on asthma morbidity in general practice. Lancet. 1986; 327(8471): 26-9. DOI: 10.1016/s0140-6736(86)91904-5 